\title{
General paper \\ CHARACTERIZATION OF INTEGRATED DATA ON INHERENT FLAWS IN ENGINEERING CERAMICS
}

\author{
Toshihiko Hoshide and Hidehiko HIRAMATSU \\ Department of Energy Conversion Science, \\ Graduate School of Energy Science, Kyoto University, \\ Sakyo-ku, Kyoto 606-8501, Japan
}

\begin{abstract}
Integrated data on inherent flaws in engineering ceramics were characterized for quantitative analyses of them. For this purpose, a ceramic strength database utilized on a personal computer was temporarily constructed so that collected data on flaws could be compiled as records in the database. It was clarified that distributions of the equivalent crack length $l$ for several ceramics were nearly fitted to normal distribution functions. The distribution of $l$ was investigated for every type of flaw, and it was found to shift toward a longer length region in the order of embedded, surface, and corner flaws. The flaw data were also correlated with strength and microstructural parameters. In the relation to the strength, the strength was reduced as a whole with the decrease in the crack length, while the lower bound of strength scatter was predicted by a modified relation of the fracture mechanics criterion for long cracks. It was revealed that the flaw size increased with the increase in the grain size or the porosity. The relation of a Petch-Hall type was observed between the grain size and the mean strength estimated by using the mean value of $l$. Some useful suggestions were offered for the improvement of ceramic strength.
\end{abstract}

Key words: Ceramics, Inherent flaw, Data characterization, Strength, Flaw size, Flaw type, Statistical distribution, Grain size, Porosity, Database

\section{INTRODUCTION}

In engineering ceramics, inherent flaws are inevitably generated during material processing and subsequent machining [e.g., 1]. Although ceramics are expected as high-performance structural materials, strength properties of ceramics are unfortunately sensitive to such inherent flaws in an ambient atmosphere because of the difficulty of dislocation motion in ceramics [e.g., 2]. The quantitative characterization of integrated data on inherent flaws in ceramics is very useful for a comprehensive understanding of the relation between strength and flaw, and also in offering some suggestions for the improvement of material and/or mechanical design of ceramic components. In the characteristic analysis, it is desirable for convenience of data processing that a computer-readable database is constructed by compiling collected data on flaws. There exit excellent databases on ceramic strength $[3,4]$, though it is regrettable that they provide us no information on inherent flaws.

In this paper, data on inherent flaws in previous works are first collected into a simple and usable database of ceramic strength, which is based on a prototype established before [5]. By using the database, the flaw data are quantitatively characterized, and correlated with strength and microstructural parameters. The resultant correlations are also discussed.

2. TEMPORARY DATABASE FOR CHARACTERIZING INFORMATION ON FLAWS

\subsection{Outline of Database}

As the first step, a temporary database is tenta- tively constructed by collecting data available in previous strength tests [6-10], in which inherent flaws have been observed as fracture origins. Of course, more data should be required to complete the database.

The database is edited in a format of Microsoft (the registered trademark) Excel, which enable us to characterize information on flaws and to elucidate its relation to other parameters on a personal computer. An actual format is reconstructed based on the format which has been established for the ceramic strength [3]. The format is modified so that several kinds of data associated with inherent flaws could be contained in the database. Another modification is that a material identification (ID) is newly assigned for different strength tests using the same material. By introducing the material ID, other strength properties obtained for the same material can be retrieved more easily on a computer.

\subsection{Contents of Database}

\subsubsection{Common data}

In the present database, data fields common to strength properties are as follows; fields of reference data, material data, grinding and polishing methods, post-heat treatments, and material constants. Every field as mentioned above consists of related records. The porosity of a material is included as a record in the filed of material data, and is one of the important parameters which may reflect the material processing closely connected with strength properties. However, the porosity is rarely stated in specifications of the material under consideration or in a reference. Consequently, an apparent porosity as defined below is included in the database if the porosity is not described 
but the bulk density $\rho$ is mentioned in a cited document. By using the bulk density $\rho$ measured for a material, the apparent porosity $p_{\text {ap }}[5]$ is defined as

$$
p_{\mathrm{ap}}=1-\left(\frac{\rho}{\rho_{\mathrm{th}}}\right),
$$

where $\rho_{\text {th }}$ is the theoretical density of the material and is given for some typical ceramics elsewhere [e.g., 11]. 2.2.2. Data related to strength and flaw

The present database is prepared for strength properties obtained under testing modes of tension, compression, bending, ring compression and expansion. Data records included in the strength fields stated above are as follows; a specimen geometry, a loading mode, a testing environment, the strength, and the type, area and size of the flaw which is identified as a fracture origin. The flaw type is mainly classified by the position of the flaw observed on a fracture surface; i.e., three types of corner, surface and embedded flaws. For some materials, the flaw area is calculated by using an image-processing technique.

An equivalent crack length [6] is introduced in describing the flaw size. By using a measured flaw length $a$, an applied stress $\sigma_{\mathrm{a}}$ and its related stress intensity factor $K$, the equivalent crack length $l$ is defined as

$$
l=a M_{\mathrm{o}}^{2}=\frac{1}{\pi}\left(\frac{K}{\sigma_{\mathrm{a}}}\right)^{2} .
$$

In Eq.(2), $M_{\circ}$ is a multiplication factor for $K$ estimation and is obtained elsewhere [e.g., 12-15]. A merit of introducing $l$ is that the relation between strength and flaw size can be discussed with disregard to the shape and location of a flaw or a loading mode.

\section{STRENGTH PROPERTIES AND MATE- RIALS TO BE INVESTIGATED}

This work deals with strength properties only in testing modes and in materials, in which fracture origins have been confirmed in fractographic observations. As a consequence, the strength properties intended for consideration are those under bending and ring compression modes in the present investigation.

Materials to be investigated are as follows; a pressureless sintered alumina (AL-1) produced by Japan Fine Ceramics Center, two pressureless sintered alumina ceramics with $96 \%$ and $92 \%$ purity $\left(96 \% \mathrm{Al}_{2} \mathrm{O}_{3}\right.$

Table 1. Material properties of examined ceramics.

\begin{tabular}{c|c|c|c|c}
\hline Material & $\begin{array}{c}\text { Bulk } \\
\text { density } \\
\rho, \\
\mathrm{Mg} / \mathrm{m}^{3}\end{array}$ & $\begin{array}{c}\text { Grain } \\
\text { size } \\
d, \\
\mu \mathrm{m}\end{array}$ & $\begin{array}{c}\text { Young's } \\
\text { modulus } \\
E, \\
\mathrm{GPa}\end{array}$ & $\begin{array}{c}\text { Fracture } \\
\text { toughness } \\
K_{\mathrm{IC}}, \\
\mathrm{MPa} \sqrt{\mathrm{m}}\end{array}$ \\
\hline $\mathrm{AL}-1$ & 3.93 & 5.3 & 380 & 4.4 \\
$96 \% \mathrm{Al}_{2} \mathrm{O}_{3}$ & 3.7 & 10 & 349 & 3.6 \\
$92 \% \mathrm{Al}_{2} \mathrm{O}_{3}$ & 3.6 & 20 & 290 & 3.2 \\
$\mathrm{EC}-141$ & 3.23 & 1.6 & 320 & 6.0 \\
$\mathrm{EC}-1211$ & 3.26 & 5.0 & 330 & 5.7 \\
$\mathrm{Sialon}$ & 3.22 & 2.1 & 294 & 5.8 \\
$\mathrm{PSZ}$ & 6.00 & 1.0 & 218 & 6.0 \\
\hline
\end{tabular}

and $96 \% \mathrm{Al}_{2} \mathrm{O}_{3}$ ) by Ohtake Gaishi Co. Ltd., a gas pressure sintered silicon nitride (EC-141) and a pressureless sintered silicon nitride (EC-1211) by NGK Spark Plug Co. Ltd., a pressureless sintered sialon by Shinagawa Shirorenga Co. Ltd., and a partially stabilized zirconia (PSZ) by Toray Industries Inc. Table 1 shows typical material properties of the above ceramics.

\section{FLAW CHARACTERISTICS AND THEIR RELATIONS TO OTHER PROPERTIES}

In this study, flaw data are focused on the equivalent crack length and the flaw type which have been specified in 2.2.2. Information on flaws is also correlated with strength and microstructural parameters.

\subsection{Distribution Characteristics of Flaw \\ 4.1.1. Distribution of flaw size}

Distributions of the equivalent crack length $l$ in the materials listed in Table 1 are plotted on a normal probability paper. The result is shown in Fig.1, where each straight line expresses the relation fitted to a normal distribution function. The statistics are summarized in Table 2. The distribution of $l$ is nearly fitted to the normal distribution function, except for the case of the silicon nitride EC-1211. As for EC1211 , it is clarified that the distribution is better fitted to a three-parameter Weibull distribution function rather than a normal distribution function. In fitting the data of EC-1211 to the Weibull function, the shape, scale and location parameters are also found to be $0.87,7.83 \mu \mathrm{m}$ and $2.52 \mu \mathrm{m}$, respectively.

As seen in Table 2, the mean equivalent crack length $\bar{l}$ especially in the alumina AL-1, the silicon nitride EC-141 and the zirconia PSZ are shorter than the mean length $\bar{l}$ in the other four materials. Comparing the coefficient of variation for $l$ in Table 2, the

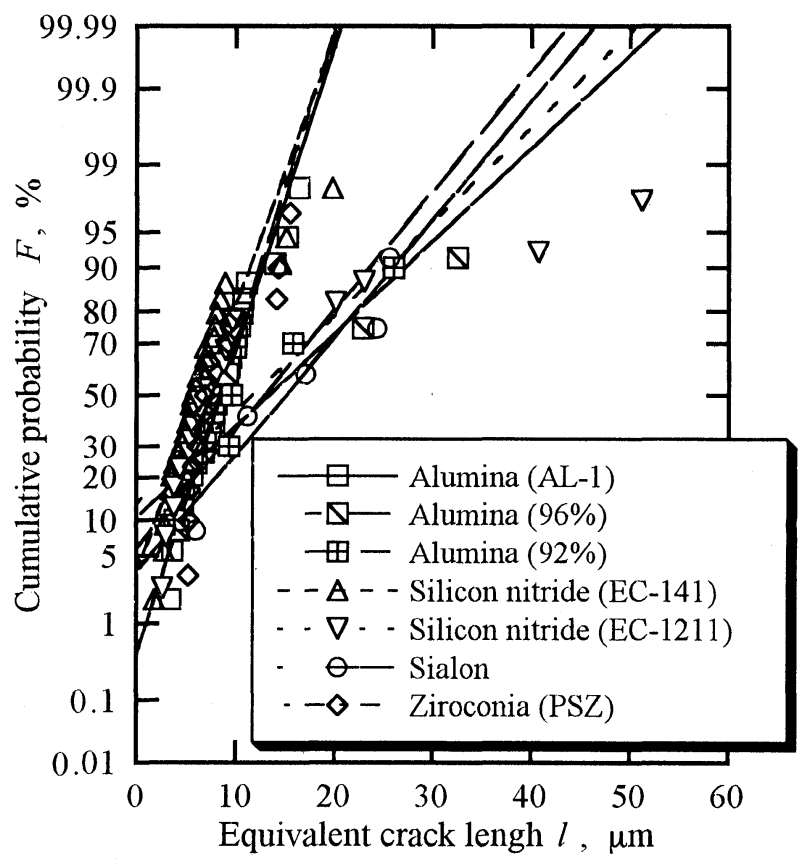

Fig.1. Distribution of equivalent crack length. 
Table 2. Statistics of equivalent crack length in various ceramics.

\begin{tabular}{c|c|c|c}
\hline Material & $\begin{array}{c}\text { Mean } \\
\text { crack length } \\
\bar{l}, \mu \mathrm{m}\end{array}$ & $\begin{array}{c}\text { Standard } \\
\text { deviation } \\
l_{\sigma}, \mu \mathrm{m}\end{array}$ & $\begin{array}{c}\text { Coefficient } \\
\text { of } \\
\text { variation }\end{array}$ \\
\hline $\mathrm{AL}-1$ & 8.55 & 3.30 & 0.386 \\
$96 \% \mathrm{Al}_{2} \mathrm{O}_{3}$ & 13.4 & 11.6 & 0.899 \\
$92 \% \mathrm{Al}_{2} \mathrm{O}_{3}$ & 12.9 & 8.44 & 0.654 \\
$\mathrm{EC}-141$ & 6.65 & 4.09 & 0.615 \\
$\mathrm{EC}-1211$ & 11.7 & 12.9 & 1.103 \\
$\mathrm{Sialon}$ & 15.1 & 8.64 & 0.572 \\
$\mathrm{PSZ}$ & 8.32 & 3.51 & 0.422 \\
\hline
\end{tabular}

scatter of $l$ is found to be smaller in the alumina AL- 1 and the zirconia, while a very large scatter is noticed in the silicon nitride EC-1211 in which the worst fitting to the normal distribution function is observed.

\subsubsection{Distribution of flaw type}

Figure 2 shows the proportion of flaw type to the total number of flaws for the whole group of all materials, and for each material group of alumina, silicon nitride and zirconia. In Fig.2, the data are pooled for the groups independently of other factors such as a specimen geometry, a loading mode and machining conditions. The data for the sialon, however, is not presented in Fig. 2 because types of flaws in the material have not been clarified.

As for all materials, the proportion of surface flaw is nearly equal to that of embedded flaw, and the proportion of corner flaw is about half of them. Almost similar proportions are found in the alumina and the zirconia ceramics, in which the proportion of surface flaw to the total is larger compared with ones of the other types. In the silicon nitride ceramics, however, the proportion of embedded flaw occupies around half of the total. It should be noted that the trend of the flaw proportion in an individual material may change if more data are collected for the material.

In Fig.3, the equivalent crack length $l$, which is

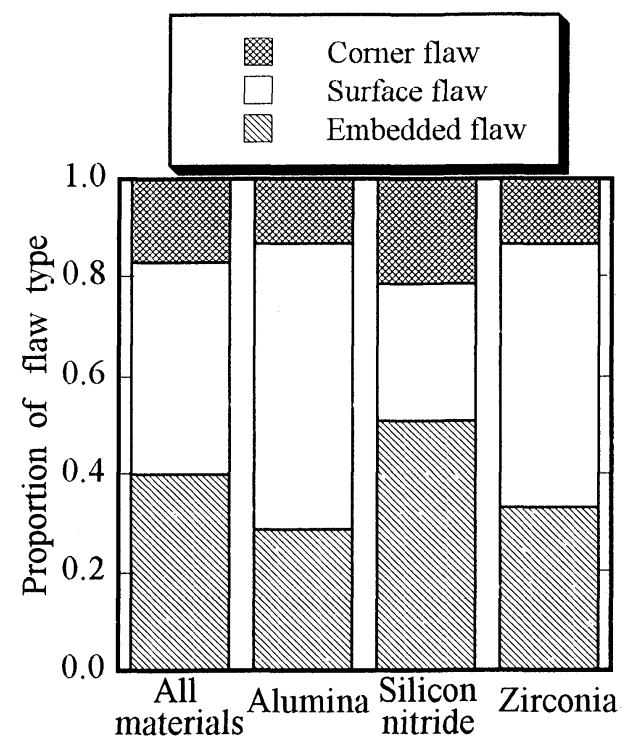

Fig.2. Histogram of flaw type.

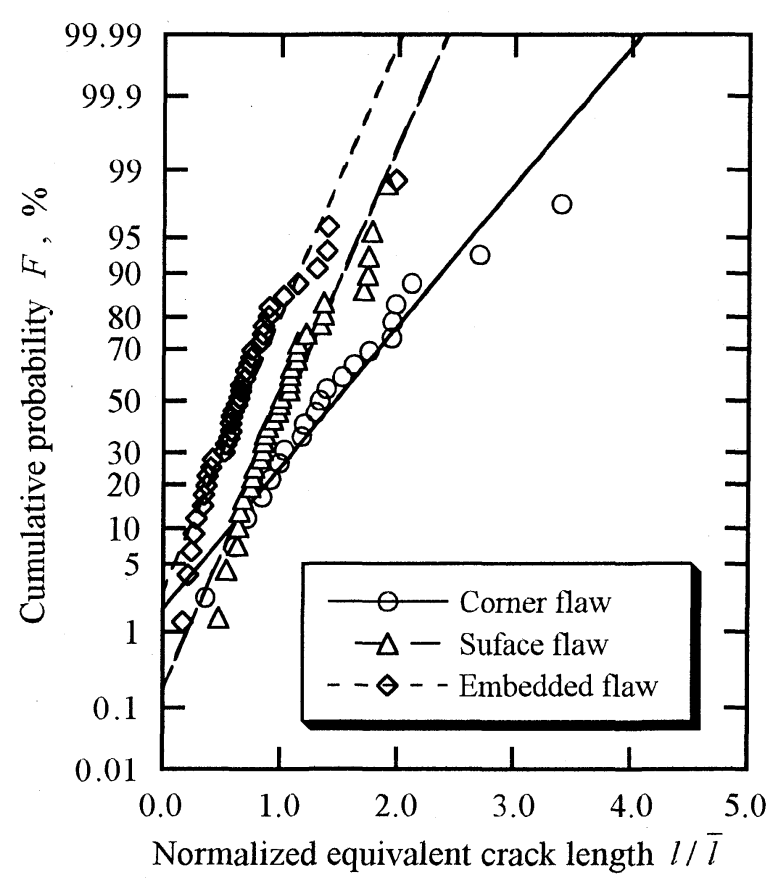

Fig.3. Distribution of normalized crack length depending on flaw type.

pooled according to the flaw type but independently of the material kind and other factors, is plotted on a normal probability paper. In this case, an individual length $l$ obtained in a material is normalized by the mean equivalent crack length $\bar{l}$ in the corresponding material. The normal distribution function fitted to the distribution of $l$ for each type of flaw is represented with a straight line in Fig.3. A well fitting to the normal distribution function is found for any type of flaw. As seen in Fig.3, the distribution of $l$ shifts toward a region of longer length in the order of the embedded, surface, and corner flaws. This suggests that a larger reduction in the ceramic strength may be caused by corner flaws.

\subsection{Relations of Strength with Size and Type of Flaw}

4.2.1. Relation between strength and flaw size

Figure 4 presents the relation between the strength and the equivalent crack length. In the figure, the strength $\sigma_{\mathrm{f}}$ and the equivalent crack length $l$ are normalized as $\sigma_{\mathrm{f}} /\left(K_{\mathrm{IC}} / \sqrt{\pi d}\right)$ and $l / d$ respectively, by using the fracture toughness $K_{\mathrm{IC}}$ and the mean grain size $d$ which are listed in Table 1 . The straight solid line in Fig. 4 represents the constant toughness criterion given by the following relation;

$$
\sigma_{\mathrm{f}}=\frac{K_{\mathrm{IC}}}{\sqrt{\pi l}}
$$

which can adequately express the relation for long cracks. In depicting the relation of Eq.(3), the strength and the crack length are also normalized as stated above. Compared with the relation of Eq.(3), the normalized strength is found to shift toward a 


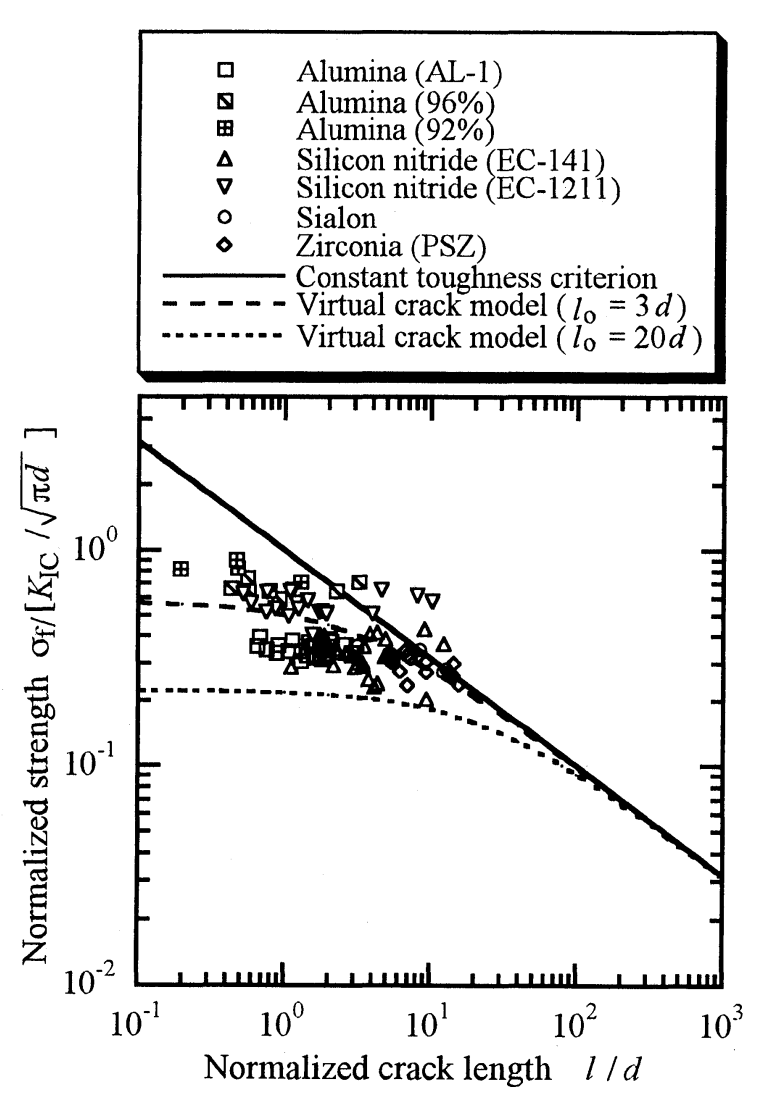

Fig.4. Relation between strength and crack length.

lower strength region with the decrease in the normalized crack length. This implies that the application of fracture mechanics parameters determined for long cracks will result in an overestimation for the ceramic strength which is dominated by smaller flaws. This anomalous behavior has also been reported in other investigations $[6-9,16-20]$.

Applying a virtual crack model [21, 22], in which a specific crack length $l_{\circ}$ is added to the original crack length $l$ in Eq.(3), the fracture criterion is reduced to

$$
\sigma_{\mathrm{f}}=\frac{K_{\mathrm{IC}}}{\sqrt{\pi\left(l+l_{\mathrm{o}}\right)}} .
$$

In Fig.4, the curve drawn with a dashed line indicates the normalized relation obtained by setting $l_{0}=3 d$ in Eq.(4). It is found that the relation with $l_{\circ}=3 d$ represent approximately the central trend in dispersed experimental results. Another relation of Eq.(4) with $l_{\mathrm{o}}=20 \mathrm{~d}$ is also drawn with a dotted line in Fig.4. It appears that the relation with $l_{\circ}=20 d$ can predict the lower bound of strength scatter in all materials. Consequently, Eq.(4) set as $l_{0}=20 d$ may be applied to a flaw-based design of ceramic components.

For instance, suppose that a dominant flaw in a ceramic component is detected by a non-destructive method. If the stress state around the detected flaw is specified and the flaw size can be converted to the maximum equivalent crack length $l_{\max }$, the minimum strength $\sigma_{\mathrm{f}, \mathrm{min}}$ of the component may be estimated as follows. By substituting $l=l_{\max }$ and $l_{\mathrm{o}}=20 d$ into
Eq.(4), the minimum strength is given by

$$
\sigma_{\mathrm{f}, \min }=\frac{K_{\mathrm{IC}}}{\sqrt{\pi\left(l_{\max }+20 d\right)}} .
$$

Actually, it is anticipated that there is an error in $l_{\max }$ evaluation. In addition, the value of $K_{\text {IC }}$ has a scatter, though the scatter is known to be much smaller than that in strength of ceramics without long cracks [e.g., $23,24]$. Therefore, the ambiguity in Eq.(5) should be still considered in the final design.

4.2.2. Strength distribution depending on flaw type

Figure 5 shows the normal distribution of strength plotted according to the flaw type. As a plot similar to Fig. 3, an individual strength $\sigma_{\mathrm{f}}$ in a material is also normalized by the mean strength $\bar{\sigma}_{\mathrm{f}}$ in the corresponding material. The fitting to the normal distribution function appears good in this case too. In a $\beta$-sialon [25], it is clearly observed that the fracture from surface flaws occurs at a lower stress than that from embedded flaws. However, it is difficult to distinguish the difference among the distributions for the three types of flaws in Fig.5, though the strength for the types of corner and surface flaws seem a little bit lower than that for the type of embedded flaw especially in a higher strength region. Considering the result in Fig. 3 together, the generation of corner and surface flaws should be inhibited for the improvement of ceramic strength.

Although the strength variation as above is expected from the relation in Fig.3, there is a difference between the variation behavior of the equivalent crack length and the strength with respect to the flaw type. The difference of strength due to the flaw type is not so remarkable as that of the crack length. A smaller

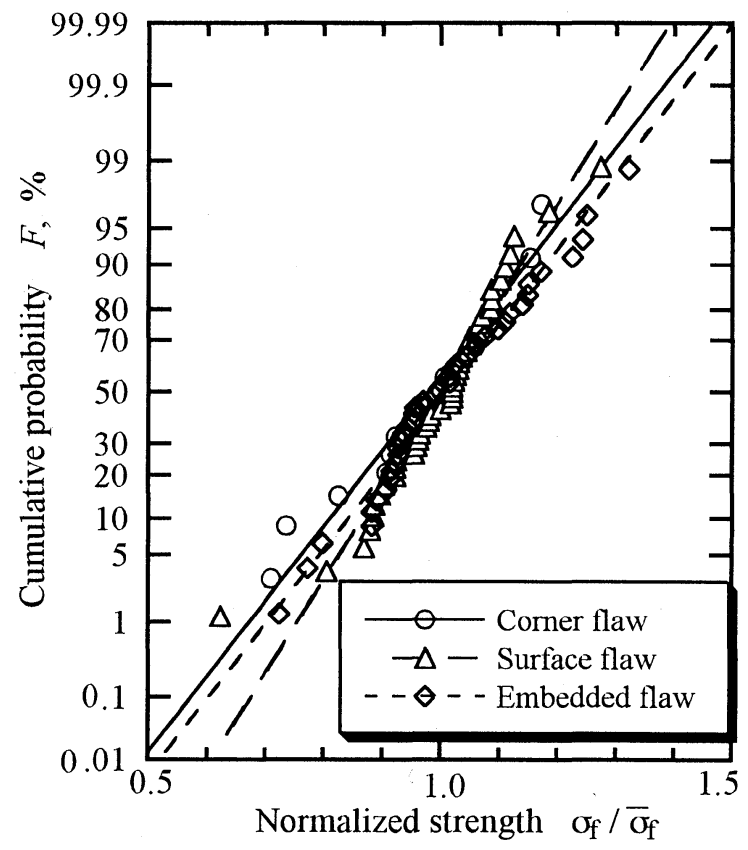

Fig.5. Distribution of normalized strength depending on flaw type. 
variation in the strength for the flaw type may be associated with the following relation between strength and crack length. The strength is a function of the square root of the crack length, to which the specific crack length is further added. This relation signifies that a variation in the crack length results in a smaller difference of the strength. This leads to the deduction that the strength is expected to be more insensitive to the flaw type than the crack length even if the difference due to the flaw type appears.

\subsection{Correlation of Flaw Size to Microstruc-} tural Parameters

4.3.1. Dependence of flaw size on grain size and porosity

The size of a flaw is supposed to depend on the microstructure of the material which contains the flaw. Figure 6 shows variations of the mean equivalent crack length $\bar{l}$ with respect to the grain size $d$ and the apparent porosity $p_{\text {ap }}$ as microstructural parameters.

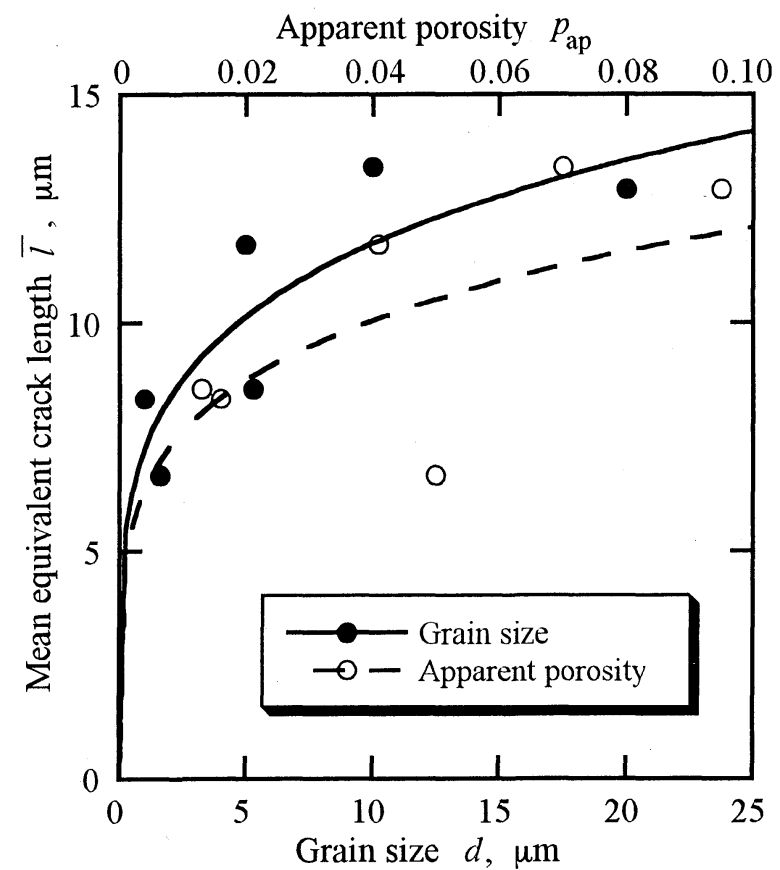

Fig.6. Relations of flaw size to grain size and porosity.

The curves in Fig.6 represent the power functions of $d$ and $p_{\text {ap }}$, which are given by

$$
\bar{l}=7.24 \times d^{0.209},
$$

and

$$
\bar{l}=21.0 \times\left(p_{\mathrm{ap}}\right)^{0.200},
$$

respectively. Although it should be noted that the material kind is different, a good correlation is observed for each parameter of the microstructure. As seen in Fig.6, the scatter of data is smaller in the correlation represented by Eq.(6) in comparison with that by Eq.(7). In fact, the correlation coefficient for Eq.(6) is higher by 0.2 than that for Eq.(7). In any case, the flaw size becomes larger with the increase in the grain size or the porosity. Consequently, it is anticipated that larger flaws may exist in a material with a coarser microstructure.

4.3.2. Flaw size correlated with Petch-Hall relationship

It is reported that the strength in brittle fracture is also correlated with the grain size by the Petch-Hall relationship [e.g., 26-28]. To examine the subject in relation to the equivalent crack length $l$, the following mean strength $\bar{\sigma}_{\mathrm{f}, l}$ is estimated by using the mean equivalent crack length $\bar{l}$.

$$
\bar{\sigma}_{\mathrm{f}, l}=\frac{K_{\mathrm{IC}}}{\sqrt{\pi \bar{l}}} .
$$

Since Eq.(8) does not take account of such crack modification for a small crack as discussed in 4.2.1, another mean strength may be defined by the crack modification based on the virtual crack model as Eq.(4). In this case, the following estimation can be derived instead of Eq.(8).

$$
\bar{\sigma}_{\mathrm{f}, l}=\frac{K_{\mathrm{IC}}}{\sqrt{\pi\left(\bar{l}+l_{\mathrm{o}}\right)}},
$$

where $l_{\circ}$ is the specific crack length similar to Eq.(4).

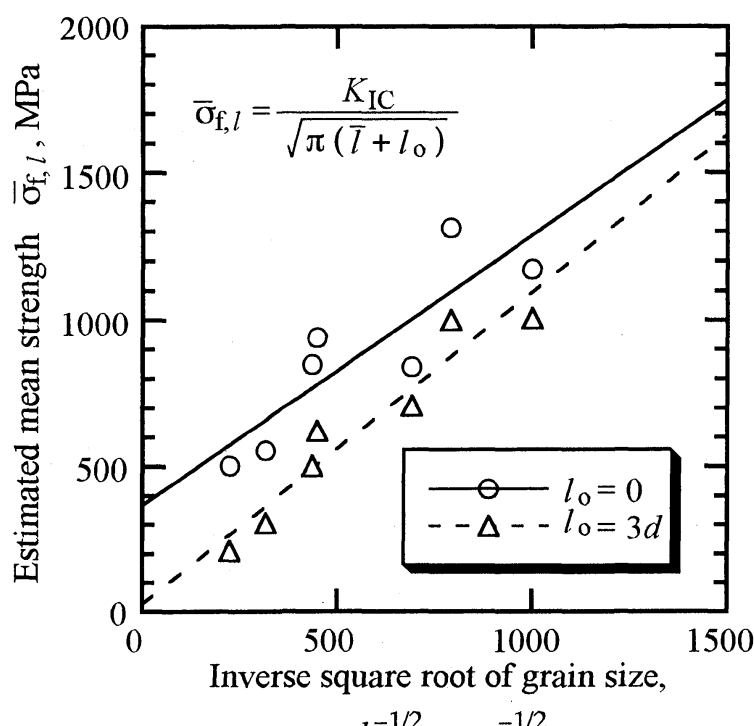

$$
d^{-1 / 2}, \mathrm{~m}^{-1 / 2}
$$

Fig.7. Estimated mean strength correlated with grain size parameter.

Figure 7 represents the relations of the inverse square root of the grain size with the mean strength $\bar{\sigma}_{f, l}$ estimated by Eq.(8) and by Eq.(9) with $l_{\circ}=3 d$ which could express the mean trend in the dispersion of experimental results. In spite of the relation obtained among different kinds of materials, Fig. 7 indicates the following relation of a Petch-Hall type for each estimation.

$$
\bar{\sigma}_{\mathrm{f}, l}=\sigma_{\mathrm{fi}}+k_{\mathrm{f}} d^{-1 / 2}
$$

where $\sigma_{\mathrm{fi}}=370 \mathrm{MPa}$ and $k_{\mathrm{f}}=0.920 \mathrm{MPa} \sqrt{\mathrm{m}}$ for Eq. $(8)$, and $\sigma_{\mathrm{fi}}=26.1 \mathrm{MPa}$ and $k_{\mathrm{f}}=1.07 \mathrm{MPa} \sqrt{\mathrm{m}}$ for Eq. (9). 
Substitution of Eq.(10) into the left side of Eq.(9) yields another evaluation for the mean equivalent crack length;

$$
\bar{l}=\frac{1}{\pi}\left(\frac{K_{\mathrm{IC}}}{\sigma_{\mathrm{fi}}+k_{\mathrm{f}} \cdot d^{-1 / 2}}\right)^{2}-l_{\mathrm{o}} .
$$

By setting $l_{0}=0$, Eq.(11) comprehends the relation given by using Eq. (8), though a higher correlation coefficient is obtained in the correlation by Eq.(9). It is noted that Eq.(11) is the function of a macroscopic parameter as well as a microscopic one, and offers the following suggestion. The flaw size becomes larger in a material with larger grains just like as stated in 4.3.1, while larger flaws are tolerated in a material with a higher toughness.

\section{CONCLUDING REMARKS}

In this study, a ceramic strength database including information on inherent flaws was temporarily constructed by collecting flaw data available in previous works. By using the database, the integrated data on flaws were quantitatively characterized, and correlated with strength and microstructural parameters.

Distributions of the equivalent crack length $l$ for most of examined ceramics were nearly fitted to normal distribution functions. To investigate the distribution of flaw type, the flaw type was classified into three types of corner, surface and embedded flaws. In the whole group of all examined ceramics, the proportion of surface flaws to the total number of flaws was almost equal to that of embedded flaws, and the proportion of corner flaws was about half of them. The equivalent crack length $l$ was pooled according to the flaw type but independently of other factors. In this case, the distribution of $l$ was found to shift toward a region of longer length in the order of the embedded, surface, and corner flaws.

As the equivalent crack length was decreased, the strength was found to be lower compared with the constant toughness criterion for long cracks. It was also revealed that the lower bound of strength scatter was predicted by the relation such that $20 d$ was added to the original crack length $l$ in the above criterion where $d$ is the grain size. The strength of fracture originating from the type of corner flaw was found to be lower than the strength from the other flaw types

It was clarified that flaws became larger with the increase in the grain size or the porosity. When the mean strength estimated using the mean crack length $\bar{l}$ was correlated with the grain size, the relation of a Petch-Hall type was observed between them.

The above results in this work provide us the following suggestions. Since there is a possibility that a larger strength reduction is caused by corner and surface flaws, the generation of such flaw types should be inhibited for the improvement of ceramic strength. A material with a coarser microstructure is expected to contain larger flaws. This point should be also considered in controlling the material processing.

\section{REFERENCES}

1. D.W. Richerson, Modern Ceramic Engineering, 2nd Ed., Marcel Dekker, Inc., New York (1992) Part II.

2. R.W. Davidge, Mechanical Behaviour of Ceramics, Cambridge University Press, Cambridge (1979) p.51.

3. Database for Ceramic Materials in MSDRD (ed. by the Research Group for Statistical Aspects of Materials Strength, Japan), (1994).

4. Ceramics Strength Database, Vol.1, ed. by Subcommittee on Strength of Ceramics, Committee on Fatigue, Soc. Mater. Sci., Japan (1996).

5. T. Hoshide, Mater. Sci. Res. Int., 4 (1998) 179.

6. T. Hoshide, H. Furuya, Y. Nagase and T. Yamada, Int. J. Fract., 26 (1984) 229.

7. J. Kitazumi, Y. Taniguchi and T. Yamada, The Memoirs of the Niihama National College of Technology (Science and Engineering) 24, (1988) 9.

8. J. Kitazumi, Y. Taniguchi, T. Hoshide and T. Yamada, J. Soc. Mater. Sci., Japan, 38 (1989) 1254.

9. T. Hoshide and M. Masuda, Mater. Sci. Res. Int., 1 (1995) 108.

10. T. Hoshide, J. Murano and R. Kusaba, Eng. Fract. Mech., 59 (1998) 655.

11. P.A. Thorton and V.J. Colangelo, Fundamentals of Engineering Materials, Prentice-Hall, Inc., Englewood Cliffs (1985) p.554

12. R.C. Shah and A.S. Kobayashi, ASTM STP 513 (1972) 3.

13. A.S. Kobayashi and A.N. Enetanya, ASTM STP 590 (1976) 477.

14. I.S. Raju and J.C. Newman, Jr., Eng. Fract. Mech., 11 (1979) 817.

15. P.M. Scott and T.W. Thorpe, Fatigue Eng. Struct. Mater., 4 (1981) 291.

16. A.G. Evans and T.G. Langdon, Progr. Mater. Sci., 21 (1976) 191.

17. S. Usami, H. Kimoto, I. Takahashi and S. Shida, Eng. Fract. Mech., 23 (1986) 745.

18. K. Tanaka, K. Suzuki and Y. Yamamoto, Proc. Int. Conf. Residual Stresses (ed. by G. Beck, S. Denis and A. Simon), Elsevier Applied Science, London (1989) 15.

19. T. Hoshide and T. Inoue, Eng. Fract. Mech., 38 (1991) 307.

20. T. Hoshide, Eng. Fract. Mech., 44, No.3 (1993) 403.

21. M.H. El Haddad, K.N. Smith and T.H. Topper, Trans. ASME, J. Eng. Mater. Technol., 101 (1979) 42.

22. T. Yamada, Proc. 31st Symp. Mater. Strength Fract., Vol.31 (ed. by T. Yokobori), Sendai (1986) 51.

23. K. Tanaka, Y. Mutoh and T. Niwa, Trans. JSME, Ser.A, 54 (1988) 1086.

24. T. Tanaka, N. Okabe, Y. Sakaida and H. Nakayama, J. Soc. Mater. Sci., Japan, 38 (1989) 261.

25. M. Mitomo, S. Nagata, M. Tsutsumi and Y. Fujii, Yogyo-Kyokai-Shi, 91 (1983) 171.

26. p.91 in Ref.2.

27. B.R. Lawn and T.R. Wilshaw, Fracture of Brittle Solids, Cambridge University Press, Cambridge (1975) p.31.

28. R.W. Hertzberg, Deformation and Fracture Mechanics of Engineering Materials, 2nd Ed., John Wiley \& Sons Inc., New York (1983) p.395. 